\title{
O USO DE MODALIZADORES LINGUÍSTICO-DISCURSIVOS NA PRODUÇÃO DO TEXTO ARGUMENTATIVO: UMA PROPOSTA DE INTERVENÇÃO/INTERFERÊNCIA EM SALA DE AULA
}

\author{
Renata Soares Souza Dias* \\ Luana Aparecida Matos Leal Fernandes** \\ Carla Roselma Athay Moraes ${ }^{* * *}$
}

RESUMO: Conhecer os modalizadores linguístico-discursivos e compreender os efeitos semânticodiscursivos que eles oferecem ao enunciado são condições básicas para o uso adequado da linguagem verbal, principalmente, em textos argumentativos. Dessa forma, apresentamos neste trabalho o resultado de uma pesquisa que estudou os efeitos de sentido provenientes dos usos de modalizadores, utilizando-os, adequadamente, no processo discursivo. Quanto aos aspectos metodológicos, optouse por um trabalho de cunho qualitativo, com um caráter exploratório. Os dados foram compostos de análises de textos produzidos por alunos do $9^{\circ}$ ano de escolaridade. Esses dados serviram de instrumentos para a pesquisa que se desenvolveu por meio de oficinas de leitura e escrita. Ao concluirmos as ações propostas, por meio do trabalho de leitura e escrita, percebemos que os alunos pesquisados compreenderam e passaram a utilizar os elementos modalizadores linguístico-discursivos e seus efeitos de sentido, sobretudo no texto argumentativo.

PALAVRAS-CHAVE: Argumentatividade; Letramento; Modalizadores.

\section{Introdução}

A língua dispõe para os falantes de vários mecanismos de (re)construção dos sentidos na linguagem. Assim, destacamos a necessidade de conhecer os modalizadores linguístico-discursivos e compreender os efeitos de sentido que eles proporcionam ao enunciado, pois são condições básicas para o uso adequado da linguagem verbal, em sua manifestação oral e escrita, principalmente em textos argumentativos. Em diversas situações, não só no

\footnotetext{
* Mestre em Letras pela Universidade Estadual de Montes Claros (Unimontes).

${ }^{*}$ Mestre em Memória: Linguagem e Sociedade pela Universidade Estadual do Sudoeste da Bahia (Uesb). Doutoranda em Estudos Linguísticos pela Universidade Federal de Uberlândia (Ufu). Professora do Instituto Federal de Educação, Ciência e Tecnologia do Norte de Minas Gerais (IFNMG), Campus Salinas.

${ }^{* * *}$ Doutora em Letras pela Pontifícia Universidade Católica de Minas Gerais (Puc-MG.). Professora adjunta da Universidade Estadual de Montes Claros (Unimontes).
} 
ambiente escolar, muitas pessoas são alfabetizadas, mas não utilizam de forma adequada os referidos recursos linguísticos e, consequentemente, prejudicam a geração dos efeitos de sentido pretendidos em seus textos.

Sobre essa situação, Soares (2009, p. 45-46) diz que "as pessoas se alfabetizam, aprendem a ler e escrever, mas não necessariamente incorporam a prática de leitura e da escrita, não necessariamente adquirem competência para envolver-se com as práticas sociais de escrita". Logo, são necessárias práticas que possibilitem ao aluno utilizar os variados recursos que a língua nos oferece para, assim, estabelecer melhores condições de veicular os efeitos de sentido pretendidos em seu texto. É primordial que a formação do aluno tenha como meta a aquisição de conhecimentos básicos, competências e habilidades, tais como: uso adequado dos modalizadores do discurso, utilização da coerência e da coesão textuais, que contribuam para que o processamento adequado do texto escrito aconteça.

Nesse aspecto, verificamos que caminhos e metas devem ser traçados, a fim de que os objetivos necessários à prática consciente de leitura e escrita sejam alcançados. Essas habilidades são fruto de um exercício que dura a vida toda e que inclui tarefas como a de organizar e de selecionar ideias, colocar-se no lugar do interlocutor e ter uma atenção constante a tudo o que ouvimos e falamos. É a esse aspecto que o nosso estudo se refere, pois os modalizadores linguístico-discursivos, foco do nosso trabalho ${ }^{1}$, são responsáveis por delinear a relação que o locutor do texto constrói com o conteúdo do enunciado e com seu interlocutor, demarcando o seu posicionamento em relação ao conteúdo apresentado. Nessa ótica, os modalizadores tornam-se um elemento de argumentação que pode conduzir o raciocínio do leitor em direção ao ponto de vista defendido no discurso.

Em determinados enunciados, uma pretensa neutralidade já indica uma tomada de postura frente ao que se está dizendo; neles o que há são efeitos de sentido de objetividade ou de subjetividade. Nessa concepção, Koch (2011, p. 17) afirma que "a neutralidade é

\footnotetext{
${ }^{1}$ Este trabalho é um recorte de uma pesquisa de dissertação de mestrado. É um estudo que uniu teoria e prática com o intuito de diagnosticar e intervir no que tange aos aspectos de produções textuais escritas, especificamente no texto argumentativo.
} 
apenas um mito: o discurso que se pretende "neutro", ingênuo, contém também uma ideologia - a da sua própria objetividade". Dessa forma, a utilização de índices modalizadores linguístico-discursivos é um recurso que o locutor utiliza para, em sua enunciação, explicitar o seu ponto de vista, a posição assumida no enunciado. Eles permitem demonstrar como o enunciador se manifesta, bem como marcam as posturas do sujeito, diante do que diz, ao elaborar o seu discurso.

Os Parâmetros Curriculares Nacionais (PCNs), no Eixo Temático I, tópico "Modalização e Argumentatividade", apresentam, enfaticamente, que a forma como falamos algo pode expressar pontos de vista, atitudes, sentimentos em relação ao que pronunciamos; pode enunciar fatos tidos como certos, duvidosos, desejáveis, entre outros. Ou seja, o locutor pode usar a linguagem de modo explicitamente argumentativo, guiando seus enunciados para conduzir a determinadas conclusões. Sinalizar para que o interlocutor reconheça se essa voz está criticando ou não, concordando ou não, além de outras marcas de enunciação.

Para Neves (2006, p. 152), todo ato de enunciar implica modalizar: “[...] Se a modalidade é, essencialmente, um conjunto de relações entre o locutor, o enunciado e a realidade objetiva, é cabível propor que não existam enunciados não modalizados”, seja por palavras ou até mesmo pela organização textual. Assim, é um fenômeno natural ao uso da linguagem sinalizar o posicionamento do autor do texto, seus objetivos, intenções e o direcionamento do texto.

Nessa perspectiva, nossa proposta de pesquisa, que resultou na escrita deste artigo, foi proporcionar aos alunos situações de produção escrita nas quais fossem reconhecidos os efeitos de sentido provenientes dos usos de modalizadores do discurso, para que, assim, utilizem-nos, adequadamente, no processo discursivo. Para isso, propusemos um trabalho integrado de leitura e escrita, no qual o aluno pôde compreender os variados sentidos que esses elementos conferem aos textos, proporcionado práticas conscientes e constantes de leitura e escrita. Isso porque o uso coerente desses elementos linguístico-discursivos pode tornar a argumentação mais efetiva, fortalecida pela via da utilização adequada de tais recursos. 
De acordo com os resultados obtidos pelas avaliações diagnósticas e pelas produções textuais produzidas pelos alunos no cotidiano em sala de aula, constatamos um baixo índice de aprendizagem de leitura e escrita em uma turma de $9^{\circ}$ ano do Ensino Fundamental. Percebemos, especificamente, uma necessidade maior de desenvolvermos uma intervenção, no que concerne aos modalizadores linguístico-discursivos, pois os alunos não fazem uso desses recursos adequadamente. Isso é perceptível, pois, no momento de analisar esses recursos dentro de um texto, não compreendem os efeitos de sentido produzidos. A falta de reflexão sobre o uso dos modalizadores por parte dos alunos também é notável com base nos problemas relativos ao sentido dos textos que costumam produzir. Foi a partir desse diagnóstico que desenvolvemos nossa pesquisa, ofertando aos alunos da referida turma, oficinas de leitura e produção textual, voltadas para o conhecimento, compreensão e uso dos recursos linguístico-discursivos, especificamente, os modalizadores argumentativos.

Efetivar o estudo de recursos de modalização da língua é direcionar os alunos à compreensão de textos e favorecer uma construção de sentido coerente em suas argumentações. Nesse sentido, apresentamos neste artigo, os resultados desse trabalho de intervenção-interferência, proposto aos alunos do $9^{\circ}$ ano do Ensino Fundamental em relação ao uso dos modalizadores argumentativos em textos produzidos em sala de aula.

No primeiro momento, trazemos um recorte dos principais aspectos teóricos que nortearam a pesquisa, delimitando também os conceitos utilizados na análise. Em seguida, no tópico relativo aos procedimentos metodológicos, esclarecemos o percurso realizado, inclusive com a apresentação de uma análise preliminar realizada no início da pesquisa, quando ainda eram feitas atividades diagnósticas. Por fim, apresentamos a análise de um dos textos produzidos pelos alunos já no processo de intervenção/oficinas e um apanhado quantitativo/qualitativo sobre o uso dos modalizadores em todos os textos produzidos pelos alunos da turma pesquisada. 


\section{Aspectos teóricos}

O estudo teórico, sistematizado a partir dos aspectos acima mencionados, fornecenos o embasamento necessário para fundamentar este trabalho, respaldando a nossa discussão. Embasamo-nos nas teorias relacionadas à leitura, à escrita, à modalização e à argumentação, propondo compreender o baixo desempenho dos alunos no que se refere à utilização, de forma efetiva, dos modalizadores, ao construir uma argumentação e, assim, agir de forma interventiva. Para isso, ancoramo-nos nas teorizações de Bakhtin (2000), (2006), Charaudeau (2008), Machado (2001), Koch (2003), (2011), entre outros que apresentam estudos relevantes à pesquisa desenvolvida.

Ressaltamos que aplicamos, também, as concepções e orientações propostas nos PCNs de Língua Portuguesa. Eles apresentam os objetivos gerais da área, que expressam capacidades que os alunos devem desenvolver ao longo da escolaridade obrigatória, explicitando a contribuição específica dos diferentes âmbitos do conhecimento. Esse documento explicita como, na nossa área, os professores podem contribuir para o desenvolvimento dos processos de letramento. Por isso, consideramos importante trazer para a fundamentação teórica deste trabalho o que nos apresentam os PCNs sobre o ensino de Língua Portuguesa.

\section{Linguagem e interação}

As atividades humanas, em sua variedade, estão sempre relacionadas à utilização da linguagem. Esta pode ser considerada como a capacidade humana de manifestar conteúdos simbólicos, visando à expressão de sentimentos, à manifestação de desejos e opiniões, à troca de informações entre grupos sociais. Por outro lado, o uso da linguagem pode servir também à manipulação de ideias, à apropriação da língua com vistas à dissimulação de intenções, daí a necessidade de decifrarmos os sentidos dos textos com os quais nos deparamos e de, também, na escrita, aprendermos a operar com a língua na construção dos sentidos dos nossos textos. Por meio dela, sinalizamos para o nosso interlocutor os efeitos de sentido oriundos dos elementos linguístico-discursivos utilizados, para que ele seja capaz 
de identificar a intenção presente em um determinado discurso. Num sentido mais genérico, a linguagem pode ser conceituada como um sistema de sinais de que se valem os indivíduos para comunicar-se. Tendo em vista essa concepção, Charaudeau (2008) afirma:

[é] a linguagem que permite ao homem pensar e agir. Pois não há ação sem pensamento, nem pensamento sem linguagem. É também a linguagem que permite ao homem viver em sociedade. Sem a linguagem, ele não saberia como entrar em contato com os outros, como estabelecer vínculos psicológicos e sociais com esse outro que é, ao mesmo tempo, semelhante e diferente (CHARAUDEAU, 2008, p. 07).

Assim, a linguagem está associada a fenômenos sociais de comunicação, em que se estabelece uma conexão entre locutor e interlocutor. Reafirmamos, assim, o grau de relevância que a linguagem possui, visto que, nela, estão entrelaçados os atos comunicativos do sujeito.

Com esse olhar, evidenciamos que o ato da linguagem é um rico e complexo fenômeno, um exercício que se utiliza de vários componentes linguísticos e situacionais. E a palavra é um desses mecanismos da linguagem que serve de interação entre o locutor e interlocutor. Isso se confirma, claramente, nas palavras de Bakhtin (2006, p. 115): “[a] palavra é uma espécie de ponte lançada entre mim e os outros. Se ela se apoia sobre mim numa extremidade, na outra se apoia sobre o meu interlocutor. A palavra é o território comum do locutor e do interlocutor".

Postulando essa ideia, Bakhtin (2006, p. 116) pontua, ainda, que "a situação e os participantes mais imediatos determinam a forma e o estilo ocasionais da enunciação". Dessa forma, a linguagem é vista como um processo de interação entre sujeitos, não mais separada do contexto em que é produzida. Logo, o sentido não está nas formas da língua, mas num conjunto de elementos produtores de sentido, que se atualizam na interação.

Bakhtin (2000) assevera que todo uso de linguagem retrata uma atividade sociointerativa a qual reflete as condições sócio-históricas da comunidade linguística ao mesmo tempo em que é por elas conduzido. Nota-se que o texto configura-se como um exercício 
intersubjetivo, uma vez que é na interação produtor-texto-leitor, em dada situação de interação, e sob condições sócio-históricas, que o sentido é construído.

Ao observar os procedimentos adotados em textos argumentativos para provocar efeito persuasivo no leitor, verificamos que os modalizadores assumem um papel indispensável no delineamento das ideias e das opiniões circunscritas pela forma como o produtor se relaciona com seu enunciado. A modalização retrata pontos de vista e sinaliza o tipo de interlocução pretendida. Considerando o texto argumentativo, a modalização está relacionada a um dos recursos linguísticos que orientam a construção de sentido, agindo sobre o interlocutor, conforme os intuitos que motivam a interação desejada.

Sobre o texto argumentativo, postula-se que ele é delineado como um texto fundamentado em argumentos e opiniões, no qual o produtor assume uma posição frente a um tema e tenta persuadir o interlocutor a aderir a tal posição. Fiorin $(2015$, p. 19) destaca que "os argumentos são os raciocínios que se destinam a persuadir, isto é, a convencer ou a comover, ambos meios igualmente válidos de levar a aceitar uma determinada tese". Portanto, estratégias linguísticas adequadas precisam ser utilizadas para conquistar a adesão do interlocutor ao seu discurso, levar o leitor a aceitar a orientação argumentativa proposta.

É fundamental frisar que, quanto mais conhecemos os elementos/mecanismos linguísticos que podem ajudar nessa tarefa, mais podemos aprimorar a nossa argumentação. Fiorin (2015, p. 15) postula que "é um lugar-comum na linguística atual afirmação de que a argumentatividade é intrínseca à linguagem humana e de que, portanto, todos os enunciados são argumentativos". Resta-nos, então, saber adequá-la à situação de uso e ao contexto social. Dessa maneira, vamos participando efetivamente de diferentes situações comunicativas nas quais temos de argumentar em função dos vários papéis que precisamos assumir na sociedade. Isso tanto em situações de exames que exigem essa competência quanto ao longo de nossa existência.

O produtor organiza seu texto em função de um querer dizer (Koch, 2003), valendo-se de estratégias diversas que possam favorecer seu projeto do dizer. Portanto, o texto precisa de um planejamento, desde a sua estrutura, as palavras, os argumentos, os 
exemplos para convencer e chegar a persuadir o leitor. Vários recursos precisam ser utilizados para que o texto alcance o objetivo desejado.

Portanto, o processo de ensino, ao ser baseado em práticas sociais, relacionado a situações de uso reais, torna-se enriquecedor. Se o objetivo do ensino da língua é instrumentalizar o aluno para que possa compreender e participar de situações comunicativas relativas às diversas esferas sociais de atividade, não há como cumpri-lo, senão tomando as situações de comunicação como ponto de partida. Ao exercer essa prática de ensino, o aluno se tornará cada vez mais consciente de sua cidadania e a exercerá, buscando soluções que visem ao bem-estar pessoal e da coletividade.

\section{Modalizadores linguístico-discursivos}

Os modalizadores são elementos linguístico-discursivos responsáveis por demarcar a relação que o locutor do texto estabelece com o conteúdo do enunciado que produz e com seu interlocutor, pontuando o posicionamento em relação ao conteúdo proposto. Esse posicionamento pode ser de completa adesão ao enunciado ou não, pois pode querer demonstrar apenas uma pretensa neutralidade sobre o assunto, como estratégia, também, de persuadir o interlocutor.

Reconhecer e saber utilizar, adequadamente, esses mecanismos de modalização possibilitam verificar o posicionamento do enunciador frente ao enunciado, assim o locutor construirá sua avaliação relacionada ao conteúdo da mensagem. Ao realizar essa análise, é possível pontuar o grau de engajamento do locutor ou de seu afastamento em relação ao que comunica. E, consequentemente, esse exercício de averiguação do compromisso assumido pelo enunciador possibilita verificar o papel da subjetividade na construção do discurso.

Koch (2011) apresenta uma definição em relação aos modalizadores:

Dentro de uma teoria da linguagem que leva em conta a enunciação, consideram-se modalizadores todos os elementos linguísticos diretamente ligados ao evento de produção do enunciado e que funcionam como indicadores das intenções, sentimentos e atitudes do 
locutor com relação ao seu discurso. (KOCH, 2011, p. 133, grifo nosso)

Ao darmos enfoque ao estudo dos modalizadores linguístico-discursivos no texto argumentativo, estamos proporcionando aos alunos a possibilidade de expor, coerentemente, suas opiniões em tais textos, pois esses mecanismos linguísticos têm a função de determinar o sentido, as posições que o sujeito/locutor assume ao dizer algo. Tais mecanismos da língua caracterizam os tipos de atos de discurso que deseja realizar. Diversas expressões linguísticas se estabelecem como formas modalizadoras de um enunciado, conferindo a ele o posicionamento pretendido pelo sujeito comunicante. Algumas ocorrências podem aparecer através de expressões verbais como: “Eu penso que...”, "É possível que...”, "É evidente que..."; por meio de advérbios e locuções verbais; através de pontuações que possibilitam identificar o tom do enunciado. Além desses exemplos citados, outros elementos linguísticos se realizam, modalizando o discurso.

Esses recursos contribuem para construção do texto, uma vez que eles possibilitam que os argumentos a serem apresentados sejam construídos, de forma coerente, no processo textual. Logo, no processo de interação, os sujeitos modalizam seu discurso para atingir seus objetivos no ato comunicativo.

Machado (2001) esclarece que a modalização é vista como uma categoria conceitual, visto que abrange vários meios de expressão, que possibilitam ao sujeito falante demarcar suas posições e intenções na comunicação. Assim, a modalização vai ser constituída por atos enunciativos, que equivalem a uma tomada de posição individual do locutor em relação ao seu ato de locução.

Machado (2001) ainda expõe que o sujeito-enunciador pode expressar sua atitude, no tocante ao conteúdo proposicional de seu enunciado, das seguintes maneiras:

I) através de marcas formais explícitas, que podem estar presentes em:-verbos: “Eu penso que...", “Eu devo...", “Eu duvido que...” etc.;- advérbios e locuções adverbiais: "sem dúvida”, "talvez", "incontestavelmente", etc.;-adjetivos, em construções pessoais: “É lindo, lindo!” ou "horrível”, “espantoso”; “É pro- 
vável que”, “Isso é meio duvidoso...”, etc.;-entonações, pontuações, que darão, conforme o caso, um tom imperativo, interrogativo ao ato de linguagem.

II) através do contexto ou situação de comunicação:- às vezes, hesitações ou repetições na enunciação podem ser índices de modalidades. Neste caso, é difícil definir qual é o tipo de modalidade: ela vai se inserir no implícito do discurso e este depende da situação de comunicação (MACHADO, 2001, p. 70, grifos nossos).

Na visão de Machado (2001, p. 70-71), esses marcadores de modalidade citados podem estar presentes e/ou relacionar às seguintes categorias por ela propostas ${ }^{2}$ :

i) a das modalidades lógicas, suscetíveis de refletir as diferentes nuances do provável, do possível, da necessidade e da eventualidade; ii) a das modalidades apreciativas que podem evidenciar as opiniões, os julgamentos, as apreciações;

iii) a das modalidades de topicalização que colocariam em destaque uma determinada parte do enunciado;

iv) a das modalidades intersubjetivas que tratariam das relações que os enunciadores mantém (sic) com seus interlocutores;

v) a das modalidades autoreferenciais, onde incluiremos a autoironia, a auto-crítica, a retificação do dito, enfim, todos os atos linguageiros pelos quais nos referimos aos nossos próprios ditos;

vi)a das modalidades interdiscursivas, ou seja, aquelas em que são evidenciadas a heterogeneidade dos sujeitos participantes do ato de linguagem (MACHADO, 2001, p. 70, grifos nossos).

Ao realizar essa categorização, a autora esclarece que as marcas formais explícitas em um texto podem gerar modalidades que são possíveis de serem encaixadas em uma ou em várias das categorias supracitadas.

Vimos, então, que a produção do enunciado pode ser perpassada por vários elementos modalizadores, sejam eles explícitos, sejam eles implícitos. São elementos que contribuem para deixar as marcas que demonstram sua posição face à determinada situação comunicativa, pois o locutor manifesta suas intenções e sua atitude perante os enunciados que produz através de elementos modalizadores. Estes se apresentam por meio dos diversos modos de lexicalização que a língua oferece, isto é, os operadores modais. 
Koch (2011) realiza uma apresentação exemplificada dos tipos de lexicalização possíveis que as modalidades podem possuir. Nessa exemplificação, há um detalhamento maior sobre o que foi apresentado por Machado (2001) em relação às marcas formais:

a) Performativos explícitos: eu ordeno, eu proíbo, eu permito etc.;

b) Auxiliares modais: poder, dever, querer, precisar etc.;

c) Predicados cristalizados: é certo, é preciso, é necessário, é provável etc.;

d) Advérbios modalizadores: provavelmente, certamente, necessariamente, possivelmente etc.;

e) Formas verbais perifrásticas: dever, poder, querer etc. + infinitivo;

f) Modos e tempos verbais: imperativo; certos empregos de subjuntivo; uso do futuro do pretérito com valor de probabilidade, hipótese, notícia não confirmada; uso do imperfeito do indicativo com valor de irrealidade etc.;

g) Verbos de atitude proposicional: eu creio, eu sei, eu duvido, eu acho etc.;

h) Entonação: (que permite, por ex.: distinguir uma ordem de um pedido, na linguagem oral);

i) Operadores argumentativos: pouco, um pouco, quase, apenas, mesmo etc. (KOCH, 2011, p. 84).

Essa descrição retirada de Koch (2011) permite observar o grau de importância que os modalizadores apresentam no discurso, possibilitando ao locutor efetivar marcas que ora demonstram distanciamento do que é enunciado, ora revelam maior grau de engajamento com relação ao que é enunciado, indicando os tipos de envolvimento e intenções que pretende veicular ao interlocutor.

Ainda em relação aos modalizadores, os linguistas Castilho e Castilho (1993) postulam que o termo modalização transmite um julgamento do falante diante da proposição, e agrupam os modalizadores em três categorias: Modalização Epistêmica, Deôntica e Afetiva. $^{3}$

${ }^{3}$ A definição de cada categoria, estabelecida por Castilho e Castilho (1993), está detalhada na tabela 1, na qual apresentamos também as ocorrências dos modalizadores nas produções dos alunos após a intervenção por meio das oficinas. 


\section{Procedimentos metodológicos}

Como apresentado no resumo deste artigo, este trabalho é um recorte de uma pesquisa, que analisa os efeitos de sentido provenientes dos usos de modalizadores linguísticodiscursivos, utilizando-os, adequadamente, no processo discursivo. A pesquisa realizada é de cunho qualitativo, uma vez que ela possui um caráter exploratório, que estimula os envolvidos a pensar e a se expressar livremente sobre o assunto em questão. Os dados são retratados por meio de análises de textos produzidos pelos alunos pesquisados,

De acordo com Minayo (1995),

[a] pesquisa qualitativa responde a questões muito particulares. Ela se preocupa, nas ciências sociais, com um nível de realidade que não pode ser quantificado, ou seja, ela trabalha com o universo de significados, motivos, aspirações, crenças, valores e atitudes, o que corresponde a um espaço mais profundo das relações dos processos e dos fenômenos que não podem ser reduzidos à operacionalização de variáveis (MINAYO, 1995, p. 21-22).

Com essa mesma ideia, Gil (2002) complementa que a pesquisa qualitativa considera que há uma relação dinâmica entre o mundo real e o sujeito; quer dizer, existe um vínculo entre o mundo objetivo e a subjetividade do sujeito, que não pode ser apresentado em números.

A partir da pesquisa qualitativa, tendo como referência uma pesquisa bibliográfica que serve de respaldo às reflexões, é desenvolvida a pesquisa-ação, que propõe uma forma de ação planejada. Este trabalho justifica-se ao unir teoria e prática, por meio da metodologia que envolve a pesquisa-ação, possibilita uma ação concreta dentro do universo pesquisado, não se limitando, então, apenas à pesquisa bibliográfica. Ao discutir a pesquisaação, Thiollent (1994) afirma que esse tipo de pesquisa deve provocar algum tipo de transformação na realidade dos participantes.

Dessa maneira, o presente trabalho possibilita essa mudança através de uma ação efetiva, associada ao estudo da bibliografia que trata do assunto proposto. Sua utilização como forma metodológica possibilita aos participantes maneiras de investigar sua própria prática de forma crítica e reflexiva. 
Com o intento de colocar em execução a proposta de intervenção, optamos por utilizar, de forma adaptada, a metodologia Sequência Didática, profícua para direcionar o trabalho com gêneros textuais. Constata-se que a essência desse procedimento de ensino é a divisão e execução. Dessa forma, as etapas da intervenção podem ser assim esquematizadas: I-instigar a argumentatividade; II- analisar o posicionamento do autor; III-identificar características e particularidades do gênero opinativo; IV-reconhecer elementos que revelam a intenção do locutor: uso dos modalizadores; V- desenvolver a oralidade: argumentos e contra-argumentos; VI- enfatizar a temática; VII- produzir textos de forma coletiva; VIIproduzir textos individualmente.

Os dados aqui apresentados foram compostos de análises de textos produzidos por alunos do $9^{\circ}$ ano do Ensino Fundamental que participaram de um projeto de intervenção com vistas à produção de textos, focalizando o uso dos modalizadores argumentativos. ${ }^{4}$

Nesse projeto, os alunos foram estimulados a interagir através da intervenção, por meio de oficinas pedagógicas, com o intuito de desenvolver habilidades linguístico-discursivas pelo uso dos modalizadores. Isso proporciona a eles práticas de leitura e escrita adequadas ao entendimento e à utilização de elementos de modalização com usos argumentativos em textos opinativos.

\section{Movimentos de análise}

Trazemos neste tópico uma breve demonstração de como ocorreu a intervenção na sala de aula da turma analisada, por meio de oficinas, que exploraram o uso dos modalizadores argumentativos na produção escrita dos alunos. Fazemos uma explanação de todo o processo, desde o diagnóstico e mobilização da turma para participação no projeto de pesquisa até a análise dos dados.

\footnotetext{
${ }^{4}$ Por envolver seres humanos, a pesquisa que deu origem a este artigo foi submetida a parecer pelo Comitê de Ética e Pesquisa com Seres Humanos, sendo que, por estar em consonância com as recomendações éticas e científicas, foi aprovado por meio do parecer 1.687.448, em agosto de 2016.
} 
Apresentamos inicialmente, como breve exemplificação, um fragmento inicial de texto produzido por um aluno do $9^{\circ}$ ano de escolaridade, na fase diagnóstica, em que já trabalhamos a proposta de produção argumentativa. Anteriormente à produção, discutimos sobre a temática sugerida.

Figura 01 - Texto produzido por um aluno na fase diagnóstica

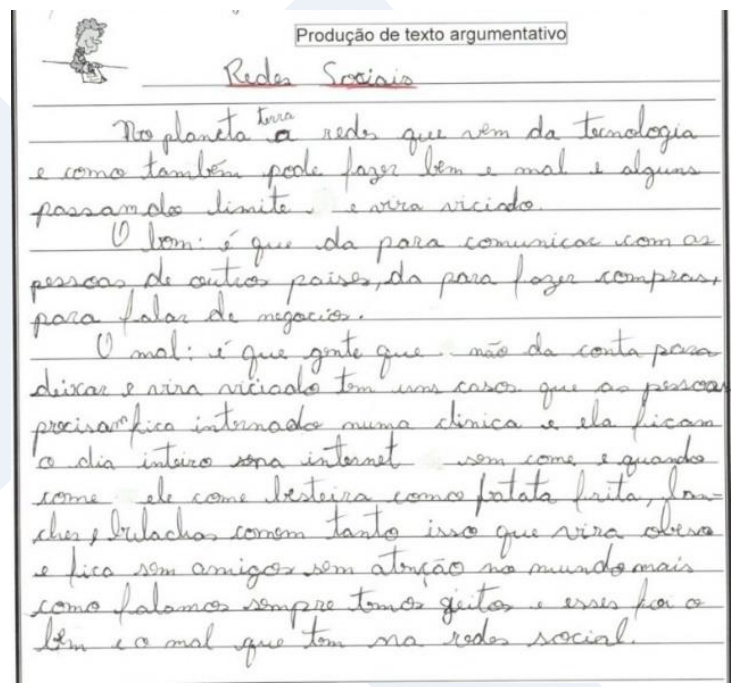

Fonte: banco de dados das pesquisadoras.

Verificamos que, nesse texto ${ }^{5}$, ocorreram problemas relacionados à utilização inadequada de alguns elementos modais que contribuiriam para a organização do sentido textual. No primeiro parágrafo, por exemplo, o autor não organizou as ideias, não explicitou ao leitor de que rede se tratava (embora fosse possível ao leitor resgatar isso no título). Por outro lado, o autor empregou índices de modalização que demonstraram coerência no ponto de vista apresentado: "O bom: é que da para comunicar com as pessoas de outros

${ }^{5}$ Nesse texto apresentado, há vários desvios na escrita. Problemas de acentuação, ortografia, pontuação, concordância, entre outros, que foram trabalhados no momento de revisão formal e reescrita do texto, mas não constituíram objeto de estudo formal por nós. 
países", "O mal: é que gente que não da conta para deixar", "vira viciado". Observamos que a modalização sinalizada e introduzida pelo uso de "O mal" prenuncia a utilização dos argumentos "vira viciado", "fica internado numa clínica", entre outras consequências que o autor enuncia logo após. Mas, no trecho "vira viciado", se fundamentado por um modalizador que indicasse princípio de possibilidade, por exemplo, "é possível que vire viciado", sua argumentação ganharia outra dimensão.

Observamos que o autor empregou alguns elementos modalizadores, todavia, em algumas passagens, o não uso de índices de modalização ocasionou algumas complicações ao texto. Os alunos, nessa etapa de escolaridade, já deveriam utilizar melhor certas estruturas indicativas de opinião como forma de articular melhor o texto; há problemas nesse texto que acabam por atrapalhar sua construção de sentido. Na segunda linha, por exemplo, o autor do texto poderia ter usado "e que, em minha opinião, podem fazer bem, mas podem também fazer mal"; assim ele generalizaria os benefícios e malefícios das redes sociais, para depois fazer o que fez: especificá-los. Situações como essas requerem um trabalho que aborde tais aspectos, para que essas habilidades sejam desenvolvidas.

Após essa atividade de diagnóstico, os alunos foram orientados sobre a intervenção a ser aplicada. Incentivamos a participação de todos, explicando a importância da escrita, especificamente quanto à argumentação, não deixando de enfatizar também a oralidade. Ressaltamos a importância do saber articular a argumentação para conseguirmos atingir o propósito comunicativo e ainda convencer os interlocutores da importância da proposta presente na nossa argumentação. Isso por intermédio do uso adequado dos modalizadores linguístico-discursivos.

A temática que norteou as oficinas foi "Intolerância", considerando-se a necessidade de discutir esse problema tão atual e agravante na sociedade em geral, tendo por objetivo a conscientização e a apresentação de propostas para intervir nesse problema social que causa tantos transtornos. Por meio desse tema, vários outros assuntos foram abordados, conforme as discussões eram norteadas. É pertinente relembrar que, ao final do En- 
sino Fundamental, os alunos precisam ter consolidadas as competências relacionadas à habilidade de expor, argumentar e opinar. Portanto, as atividades desenvolvidas apresentavam esses propósitos.

No decorrer das oficinas, foram desenvolvidas várias atividades, como análises de textos, texto lacunado, pausa protocolada, júri simulado, preparando-os para as produções, mediando o aluno, em todas as atividades, a identificar e compreender o uso dos elementos modalizadores.

Após vários módulos, preparamo-nos para a produção final. $\mathrm{O}$ tema das oficinas foi mantido, ao qual, durante esse período, os alunos tiveram acesso, de forma ampla, já que vários assuntos que norteiam essa temática foram abordados. Durante esses dias de oficina, sugerimos que os alunos pesquisassem, lessem os noticiários sobre essa temática para ficarem atentos ao que era debatido em sala de aula. Sempre ressaltamos a importância de estar inteirados com as questões sociais. Desses textos produzidos, nesta etapa final, após a intervenção, selecionamos um para a análise que fazemos a seguir, por constituir o produto final de todo o processo de intervenção.

Figura 2 - Texto produzido por uma aluna na fase pós-interventiva

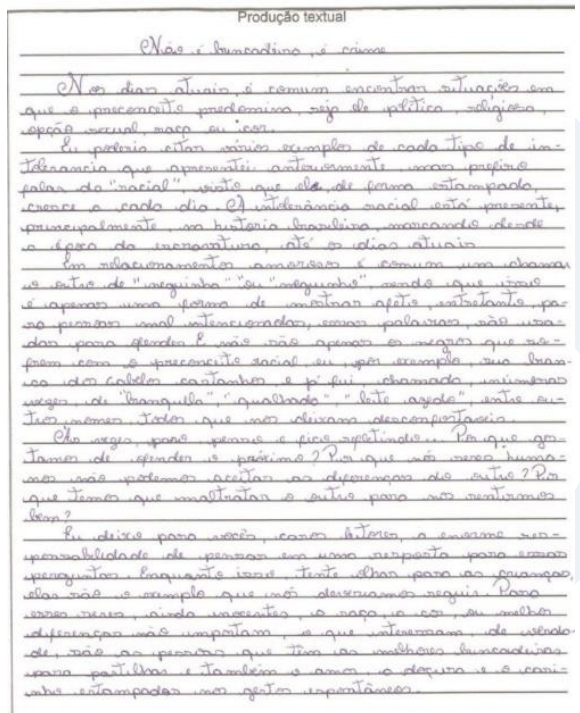

Fonte: banco de dados das pesquisadoras. 
O autor desse texto faz uso de um título instigante que dá margem ao leitor a diversas interpretações, pois se torna amplo. Diante de tantos problemas sociais, vários aspectos podem ser abordados no texto, com base nesse título, o qual consideramos atrativo, pois o leitor poderá sentir a curiosidade de saber do que se refere.

Verificamos que o primeiro parágrafo e parte do segundo servem de introdução ao assunto tratado. O locutor, de início, comenta que "é comum encontrar situações em que o preconceito predomina", sendo ele de várias formas. A partir do segundo parágrafo, ele delimita qual temática irá abordar, sendo o preconceito racial seu foco; e explica o motivo da escolha. Ainda no segundo parágrafo, aborda outro elemento relevante e comenta de onde vem o preconceito racial.

A partir do terceiro parágrafo, cita exemplos comuns do dia a dia e faz uma relação de sentido com a situação de preconceito. Cita outro exemplo, ressaltando que o preconceito racial não acontece apenas com os negros, e utiliza-se de um fato pessoal. Emprega um parágrafo inteiro com perguntas, questionamentos que incluem o leitor no discurso. Todos os questionamentos são instigantes, são argumentos que têm fundamento, questões relacionadas a valores humanos.

No último parágrafo, o autor dialoga com o leitor, chama-o, diretamente, a refletir. Deixa ao leitor a responsabilidade para pensar nas respostas das perguntas realizadas no parágrafo anterior. E, ainda, sugere que tenhamos a seguinte atitude: "[...] tente olhar para as crianças, elas são o exemplo que nós deveríamos seguir”.

Neste texto, o locutor dispõe de uma linguagem clara, com exemplos simples, mas carregados de consistência. Um texto do tipo que nos deixa atentos à leitura. No tocante aos elementos linguístico-discursivos, verificamos que vários recursos foram utilizados, proporcionando uma aproximação do leitor ao texto. Há uma forte presença de marcas verbais que identificam a responsabilidade enunciativa na construção do texto "Eu poderia citar [...]", "Paro, penso e fico refletindo", "Eu deixo para vocês”, “ e já fui chamada". Ao realizar os questionamentos retóricos, inclui o leitor, referencia-o no discurso. O recurso das aspas é recorrente em vários momentos, em um momento para dar destaque, ênfase, e em outros para se referir a expressões citadas comumente por outras pessoas. Há, ainda, a 
presença de operadores argumentativos, proporcionando articulação e continuidade ao texto: “Entretanto”, “às vezes”, "Enquanto isso”, “ainda”, “apenas”, “mas”, “visto que”, "até". Indicadores modais também foram utilizados, como "deveríamos seguir", indicando conselho; muitas proposições indicando certeza. De modo geral, apuramos que os elementos que reforçam a intenção comunicativa no texto, ou seja, os elementos modais foram bem articulados.

A seguir, expomos, por meio de uma tabela, as ocorrências dos modalizadores nas produções textuais dos alunos após a intervenção, revelando as categorias presentes. Foram analisadas 32 produções escritas, provenientes das oficinas realizadas na sala de aula durante o processo de intervenção.

Tabela 1 - Ocorrências dos modalizadores nas produções textuais dos alunos após a intervenção.

\begin{tabular}{|c|c|c|c|}
\hline $\begin{array}{c}\text { Tipo de } \\
\text { Modalização }\end{array}$ & Subtipos & Exemplos & $\begin{array}{c}\mathrm{N} .^{\circ} \mathrm{de} \\
\text { ocorrências }\end{array}$ \\
\hline \multirow[t]{3}{*}{$\begin{array}{l}\text { Epistêmica: } \\
\text { Decorre quando } \\
\text { o locutor ex- } \\
\text { pressa uma ava- } \\
\text { liação sobre o } \\
\text { valor de verdade } \\
\text { da proposição. }\end{array}$} & Asseverativa & $\begin{array}{l}\text { "Ninguém nasce odiando (...)", "Os seres humanos } \\
\text { sofrem preconceito (...)", } \\
\text { "não acho certo", "não respeitam", "não aceitam", } \\
\text { "Todos têm o direito de escolha", "o mundo será mais } \\
\text { lindo", "Eu não concordo", "A intolerância tomou } \\
\text { conta", "Eu creio (3)", "iremos continuar", "Prefiro } \\
\text { falar (3)", "Eu deixo", "Não acredito", "É certo", } \\
\text { "isso não basta", "Muitos sofrem", "acredito na ver- } \\
\text { dade", "Só através do respeito teremos um mundo } \\
\text { melhor", 'O certo é", "Acredito (2)", "É comum nos } \\
\text { dias de hoje", "Sempre foi assim". }\end{array}$ & 28 \\
\hline & $\begin{array}{c}\text { Quase } \\
\text { asseverativa }\end{array}$ & $\begin{array}{l}\text { "Se você quer ter", "parece", "Eu poderia citar", "Po- } \\
\text { derá ser", "provavelmente". }\end{array}$ & 05 \\
\hline & $\begin{array}{l}\text { Delimita- } \\
\text { dora }\end{array}$ & $\begin{array}{l}\text { "Teoricamente"(2), "Hoje em dia (2)", "Nos dias atu- } \\
\text { ais (2)", "No Brasil", } \\
\text { "Atualmente" (6), "Particularmente"( 2). }\end{array}$ & 15 \\
\hline
\end{tabular}




\begin{tabular}{|c|c|c|c|}
\hline $\begin{array}{l}\text { Deôntica } \\
\text { Indica que o fa- } \\
\text { lante considera o } \\
\text { conteúdo da } \\
\text { proposição } \\
\text { como algo que } \\
\text { deve ou precisa } \\
\text { ocorrer. }\end{array}$ & $\begin{array}{l}\text { Tem que aprender, } \\
\text { Deveriamos fazer, } \\
\text { Deviam seguir, } \\
\text { Deve respeitar (3), } \\
\text { Deveria existir, } \\
\text { Devem aceitar(3), } \\
\text { Deve pensar(2), } \\
\text { Deveriam ser (3), } \\
\text { Devemos levar, } \\
\text { Devemos educar(3), } \\
\text { Devemos apoiar, } \\
\text { Devemos ter, } \\
\text { Deve impor, } \\
\text { Deveria acabar }\end{array}$ & $\begin{array}{l}\text { Deve prevalecer, } \\
\text { Não devem brigar, } \\
\text { Precisamos aceitar (2), } \\
\text { Precisamos deixar, } \\
\text { Precisam aprender (3), } \\
\text { Precisamos preparar (2), } \\
\text { Precisam ensinar (2), } \\
\text { Temos que abrir os } \\
\text { olhos, } \\
\text { Tem que acabar (3), } \\
\text { É preciso aprender (2), } \\
\text { Devem viver, } \\
\text { Tem que respeitar (2,) } \\
\text { Podem aprender, } \\
\text { Deveria haver, } \\
\text { Tem que proporcionar, } \\
\text { Temos que aceitar }\end{array}$ & 48 \\
\hline $\begin{array}{l}\text { Afetiva } \\
\text { O falante verba- } \\
\text { liza suas reações } \\
\text { emotivas em } \\
\text { face do conte- } \\
\text { údo da proposi- } \\
\text { ção. }\end{array}$ & $\begin{array}{l}\text { Despreziveis, desconfortáveis, } \\
\text { Infelizmente (5), } \\
\text { Sinceramente (3), } \\
\text { Gradativamente, } \\
\text { Principalmente (4), } \\
\text { Gravemente, }\end{array}$ & $\begin{array}{l}\text { Primordial, } \\
\text { Necessário, } \\
\text { Bem dificil (2), } \\
\text { Irreversíveis, } \\
\text { Bem comum, } \\
\text { Extremamente difícil, } \\
\text { Simplesmente, } \\
\text { Serissimos. }\end{array}$ & 25 \\
\hline \multicolumn{3}{|c|}{ Total } & 121 \\
\hline
\end{tabular}

Fonte: Elaborado pela pesquisadora, com base na teoria de Castilho e Castilho (1993, p. 222-223).

Os elementos modalizadores presentes nos textos dos alunos não se limitaram ao que foi inserido na tabela, pois há outros recursos explícitos e, também, implícitos presentes nos textos. Fizemos uso, entretanto, nesta tabela, da categoria citada por Castilho e Castilho (1993). Assim, realizamos uma comparação com base na tabela elaborada, a partir do diagnóstico, citando as categorias postuladas por esses mesmos autores.

Verificamos nos textos dos alunos que houve um avanço nas produções textuais após a intervenção. Identificamos elevado uso dos modalizadores linguístico-discursivos nos textos e, ao analisarmos em que segmento ocorreu maior presença, vimos que foi em categorias que contribuem para adesão maior do leitor ao texto, sendo este, justamente, o nosso propósito, uma vez que trabalhamos com textos da esfera argumentativa, cuja finalidade é convencer os interlocutores das visões de mundo apresentadas.

Conforme Castilho e Castilho (1993), a modalização Epistêmica Asseverativa demonstra, em sua proposição, algo como certo, como verdadeiro. Mostra que o locutor está 
comprometido com o que fala. Possibilita ao leitor crer, notar firmeza no que está sendo proferido. Ocorreu um número considerável dessa classe de modalizadores, 28 ocorrências, e um avanço em relação aos resultados apresentados anteriormente no diagnóstico.

Verificamos que a modalização Epistêmica Quase-asseverativa apresentou baixa frequência, apenas 05. Essa categoria indica hipótese, algo provável, quase possível. Essa classe veicula a ideia de isenção na responsabilidade do que foi dito. Denotamos que nesse gênero textual não é favorável esse tipo de ocorrência, pois o locutor, dependendo da situação, não se sente obrigatoriamente responsável pelo que diz, se o engajamento foi menor. Com essa porcentagem, notamos que os alunos compreenderam que essa categoria não é relevante para esse tipo de texto.

Logo a seguir, observamos os Epistêmicos Delimitadores que estabelecem limites, isto é, restringem um sentido dentro de um campo semântico. Houve pouca ocorrência, contabilizamos 15. Notamos que, nessa categoria, o mais significativo não foram os números, mas, sobretudo as expressões utilizadas pelos alunos, as quais eram, antes, pouco presentes em seus textos. Já os modalizadores Deônticos apuramos uma presença de 48 deles; notamos um número expressivo ao analisarmos tanto os textos em relação às outras classes quanto aos números da tabela do diagnóstico. Identificamos que, nos parágrafos de desenvolvimento dos textos, ou seja, na argumentação propriamente dita e, principalmente, na conclusão, houve concentração desse recurso. Nesses segmentos do texto, há necessidade de estabelecer um caráter pontual do posicionamento do autor e de um caráter de imperatividade ao sugerir algo para amenizar ou, até mesmo, para solucionar o problema, pois prediz o que precisa acontecer.

Por fim, observamos os modalizadores Afetivos, nomeados por Bronckart (2012) de "Apreciativos". Esse grupo apresentou também um número satisfatório, detectamos 25. Esses elementos explicitaram marcas avaliativas, através de adjetivos e advérbios. Apesar de o texto ser do gênero Artigo de Opinião, não deixa de carregar traços de subjetividade. Notamos que, nessa categoria, o mais significativo não foram os números, mas, sobretudo as expressões utilizadas pelos alunos, as quais eram, antes, pouco presentes em seus textos. 
Verificamos, de modo geral, nos textos analisados após a intervenção, que ocorreu o uso satisfatório desses elementos, pois os alunos passaram a fazer uso de forma adequada, contribuindo para que o propósito comunicativo acontecesse efetivamente. Observamos, também, que até em relação à extensão textual, os que foram produzidos após a intervenção foram maiores em relação aos textos analisados no diagnóstico. Acreditamos que esse fator ocorreu por termos ofertado ao aluno uma possibilidade maior de repertório sobre o tema em estudo e por termos trabalhado de forma mais interativa, o que lhes forneceu mais segurança nos momentos de escrita dos textos.

\section{Considerações finais}

Ao desenvolvermos as ações propostas neste trabalho, reafirmamos que são necessárias práticas de leitura e escrita, a fim de que os alunos adquiram habilidades e competências eficazes para uma participação mais efetiva nas atividades sociais que requeiram letramento, engajamento social, cultural. O professor, ao dispor de um posicionamento mediador, deve ser presença capaz de conduzir, de forma efetiva, o ensino-aprendizagem com vistas ao letramento.

Este trabalho constituiu um avanço em nossa prática pedagógica, pois contribuiu com uma mudança de postura dos alunos frente ao texto e com sua inserção em práticas de letramento mais significativas para a sua vida, especificamente, no que tange à argumentação, que tem tido notoriedade nos debates a respeito de leitura e escrita, na conjuntura atual, que necessita de sujeitos ativos e conscientes de seus deveres e direitos.

Compreendemos, pela nossa experiência, que o exercício com a escrita do texto constitui uma tarefa desafiadora para o professor, já que percorre a leitura, a compreensão e a interpretação textual, processos que exigem do aluno esforço e dedicação para que as habilidades necessárias sejam atingidas. Além disso, é perceptível que os alunos não são mais os mesmos; os conteúdos e seus significados também ganharam outra proporção. É preciso que o aluno possa relacionar o conteúdo didático com seu dia a dia, perceber a importância desse conhecimento e não simplesmente aprender por aprender. É imprescindível também que o professor conheça a dificuldade do aluno para, a partir desse ponto, 
desenvolver atividades que atendam às suas reais necessidades. Citamos esses fatores devido às alterações inevitáveis do tempo e, principalmente, ao fato de que vivemos em uma sociedade que se aprimora a cada dia, que se transforma na contemporaneidade.

Em tempos de constantes transformações, é necessário perceber o quanto se deve enfatizar o aprimoramento profissional na formação continuada, sobretudo na nossa categoria profissional. Nessa perspectiva, devemos rever nossos conceitos e práticas, e, com olhar pesquisador, realizar as mudanças necessárias à prática em sala de aula. Com esse intuito, desenvolvemos este trabalho e propusemos, após o diagnóstico, uma intervenção direcionada à produção textual.

Concluímos, portanto, que, ao realizar um trabalho sequencial, reflexivo, interacional (texto/aluno/professor) e voltado para práticas sociais, os resultados, em relação à aprendizagem, foram positivos.

\title{
THE USE OF LINGUISTIC-DISCURSIVE MODALIZERS IN THE PRODUCTION OF ARGUMENTATIVE TEXT: A PROPOSED INTERVENTION / INTERFERENCE IN THE CLASSROOM
}

\begin{abstract}
To know the linguistic-discursive modalizers and understanding the semantic-discoursive effects they offer to the utterance are basic conditions for the appropriate use of the verbal language, especially in argumentative texts. Thus, we present in the article the result of a research that studied the effects of meaning originated in the use of linguistic-discursive modalizers, using these effects properly in the discursive process. Regarding the methodological aspects, opt for a qualitative work, with an exploratory character. The data were composed by analyzes of texts produced by 9 th grade students. These data were tools for this work, which was developed through reading and writing workshops. When the actions proposed in this study were completed, through reading and writing activities, we noticed the students started to understand and use the linguistic-discursive modalizers and their meaning effects, especially in argumentative text.
\end{abstract}

KEYWORDS: Argumentativity; Literature; Modalizers.

\section{REFERÊNCIAS}

BAKHTIN, M. Os gêneros do discurso. In: M. BAKHTIN. Estética da criação verbal. São Paulo: Martins Fontes, 2000. p. 277-326. . Marxismo e filosofia da linguagem. São Paulo: Hucitec, 2006. 
BRASIL. Secretaria de Educação Fundamental. Parâmetros Curriculares Nacionais: terceiro e quarto ciclos do ensino fundamental: Língua Portuguesa/Secretaria de Educação Fundamental. Brasília: MEC/SEF, 1998.

CASTILHO, A. T.; CASTILHO, C. M. M. de. Advérbios Modalizadores. In: R. ILARI (org.). Gramática do português falado. Campinas: Editora da UNICAMP, 1993. p. 213-261.

CHARAUDEAU, P. Linguagem e discurso: modos de organização. São Paulo: Contexto, 2008.

FIORIN, J. L. Argumentação. São Paulo: Contexto, 2015.

GIL, A. C. Como elaborar projetos de pesquisa. São Paulo: Editora Atlas, 2002.

KOCH, I. V. Argumentação e linguagem. 13. ed. São Paulo: Cortez, 2011. - A inter-ação pela linguagem. 8. ed. São Paulo: Contexto, 2003.

MACHADO, I. L. Breves considerações sobre índices de modalização e práticas de Leitura. Caligrama, v. 6, 2001. p. 63-77.

MINAYO, M. C. S. (Org.). Pesquisa Social: teoria, método e criatividade. Petrópolis: Vozes, 1995.

NEVES, M. H. M. Texto e gramática. São Paulo: Contexto, 2006.

SOARES, M. Letramento: um tema em três gêneros. 3. ed. Belo Horizonte: Autêntica, 2009.

THIOLLENT, M. Metodologia da pesquisa-ação. São Paulo: Cortez, 1994.

Recebido em: 30/04/2020.

Aprovado em: 03/06/2020. 